\title{
BEE PROPOLIS AS A NATURAL FEED ADDITIVE: BIOACTIVE COMPOUNDS AND EFFECTS ON RUMINAL FERMENTATION PATTERN AS WELL AS PRODUCTIVITY OF RUMINANTS
}

\author{
Y. A. SOLTAN ${ }^{1 *}$ AND A. K. PATRA ${ }^{2}$ \\ ${ }^{1}$ Department of Animal and Fish Production, Faculty of Agriculture, Alexandria University, \\ Alexandria-21545, Egypt \\ ${ }^{2}$ Department of Animal Nutrition, West BengalUniversity of Animal and Fishery Sciences, West \\ Bengal, Kolkata-700 037, India
}

\begin{abstract}
Propolis, a resinous substance collected by honeybees, has long been recognized for its medicinal and health-promoting functional properties. Recently it has been considered as a natural alternative feed additive to antibiotics in ruminant diets to modulate ruminal microbiota and their fermentation patterns favorably. Propolis exists in various colors and types with no standard chemical composition because its composition is highly variable depending upon the bee collection, vegetation sites, season, and types of bees. Over 300 compounds with different structures and isomers have been identified in propolis in the literature, among of which phenolic acids, flavonoids and terpene components are the most common bioactive chemical constitutes found in all propolis types. These chemical constitutes are characterized by powerful antimicrobial, immuno-stimulatory and antioxidant activities, and thus they are believed to contribute significantly to the nutritional effects of propolis for ruminants. This review discusses the remarkable nutritional effects of different types of propolis to assess the most common effects of propolis as feed additive for ruminants including feed intake, rumen fermentation, methanogenesis, nitrogen metabolism, nutrient utilization, ruminal microbial populations, and quantity and quality of the final products (meat and milk). Further, discussion has been made regarding processing of propolis such as nano-form propolis, which possess more antibacterial and antifungal efficiency than the normal form of propolis.
\end{abstract}

Key words: Microbiota, Nutrient utilization, Nanopropolis, Propolis, Ruminal fermentation

\section{Introduction}

Propolis or bee glue is a resinous substance collected by honeybees (Apis mellifera), from exudates and buds of various species of trees and plants, mixed with wax and pollen, and modified by enzymes secreted by bees (Seven et al., 2010). The word propolis has derived from two parts "pro" and "polis", which stand for "defense" and "city", respectively in Greek, and thus propolis is the "defense of the hive" (Kocot et al., 2018). Bees utilize propolis mainly for sealing holes and cracks, protecting the hive against microorganisms and strange predators, and preventing the fluctuations in temperature of the bee hive (Zhou et al., 2008). Brazil and China are the main producers of propolis; however it exists in all over the world and is known for its medical uses since ancient times. The ancient Egyptians used it in embalming, the Greeks used it in wound treatment, and the Persians used it to treat eczemas. It has, however, only been investigated in the last decades for its bioactive components and biological properties. 
Propolis possess antioxidant, antibacterial, antifungal, antiviral, anti-inflammatory, antiparasitic, antimethanogenic, immunemodulatory and anticancer properties, mainly because of the natural presence of effective bioactive components particularly flavonoids, phenolic acids, fatty acids, steroids, alcohols, and ketones (Morsy et al., 2013, 2015, 2016; Rufatto et al., 2018; da Silva et al., 2019).These properties together with the fact that most of its constituents are found naturally in plants make propolis safe for human and animal consumption. Therefore, it has been investigated recently as an alternative feed additive in place of dietary_ionophores antibiotics (Morsy et al., 2015).

The literature suggested that propolis has highly variable chemical composition depending upon the bee collection site, and thus its biological effects also can be varied. Accordingly, there is uncertainty of expecting specific impacts of using of propolis as feed additive by the animal holders. Propolis exists in different colors (dark brown, green, yellow, red, black and white) which vary due to the sources of resins available in the particular hive sites, and the plant geographical area visited by bees. Green and red propolis is mainly found in Brazil and Latin America, but brown propolis is found all around the world. Propolis cannot be used in crude form due to its sticky nature and it needs to be extracted by a suitable solvent. Generally, ethanol is the most effective solvent, while other solvents (e.g. methanol, ethyl ether, and chloroform) may also be used (Marcucci et al., 1998). The typical extraction method per se adds another factor for the variability among propolis types (Morsy et al., 2015). Propolis can be prepared in various forms, e.g. recently the nano propolis form possesses more antibacterial and antifungal efficiency than the normal form of propolis (Seven et al., 2018). In addition, other chemical components with nutritional effects (e.g., propylene glycol and glycerin) have been used through the preparation of propolis commercial products (Seven et al., 2018). These together with the variations of bee strains and colonies, time of the year of the collection, availability, cost, environmental and weather factors, experimental dose, and physiological status of the animals may raise the question about the optimal use of propolis as an antimicrobial feed additive for non-ruminants and ruminants. In non-ruminants, propolis supplementation has been shown to improve growth performance, digestive enzyme activity, intestinal microbiota and morphology, immune response and product quality (Kaèániová et al., 2012; Hosseini et al., 2016; Zafarnejad et al., 2017; Klaric et al., 2018; Prakatur et al., 2019). In ruminants, the various studies explored the impact of dietary different types of propolis on ruminal fermentation, nutrient utilization and production performance; however, efforts are still continuing to find a general underlying basic effect of propolis for ruminants. In this review, the effects of different propolis types in relation to their bioactive chemical components have been discussed to assess the most common effects of propolis as a feed additive to modulate ruminal microbial fermentation, nutrient utilization and production in ruminants.

\section{Propolis chemical composition}

Propolis composition is inherently associated with the floristic and ecological characteristics of plant vegetation in the collection sites visited by the bees, and thus propolis is known to have variable chemical composition (Alencar et al., 2007). However, all propolis types are complex resinous mixture which contains resin, balsam, wax, pollens, essential and aromatic oils, and impurities. Over 300 compounds in propolis have been described in the literature (Alencar et al., 2007). The main bioactive chemical classes present in all propolis types are phenolics, flavonoids and terpinenes. Based on the content of these groups, we discuss here the most common chemicals found in different 
propolis types in relation to their activity. Propolis with the same colored samples from different countries usually shows a greater resemblance in chemical composition than different colored samples from the one country (Alencar et al., 2007).

Phenolic acids: Phenolic acids are composted of a benzene ring, hydroxyl and carboxyl groups. In most propolis types, they are found mainly as benzoic and cinnamic acid, and their derivatives (Górecka et al., 2014). The most common benzoic acid derivatives found in propolis are $p$-methoxybenzoic acid, $p$-hydroxy-benzoic acid, and gallic acid. In addition, vanillic acid, proto-catechuic acid, 3,4dimethoxybenzoic acid, salicylic acid, gentisic acid, and 2-amino-3-methoxybenzoic acid can also be found (Górecka et al., 2014), while the most cinnamic acid derivatives found in propolis are $p$-coumaric acid, $o$-coumaric acid, coumarinic acid, $m$-coumaric acid, caffeic acid, isoferulic acid, ferulic acid, 3, 4- dimethoxycinnamic acid, hydrocaffeic acid, and cinnamylideneacetic acid and sinapic acid
(Scheller et al., 1990; Volpi et al., 2004; Górecka et al., 2014).

Generally, all phenolic acids exhibit antimicrobial and anti-oxidative effects. Its effect can be greater by the presence of the side chain carboxyl group (e.g., ethylene group or hydroxycinnamic acids as in cinnamic acid), additional hydroxyl groups in the aromatic ring as found in cinnamic and caffeic acids, a methoxy group in the position 3 (an electrons donor, causes the increase in the ability to stabilize aryloxy radicals) as found in ferulic acid, and the presence of an ethylene group between the phenyl ring with a carboxyl group and a hydroxy group in the para-position as in p-coumaric acid (Górecka et al., 2014).

Flavonoids: Flavonoids, a group of polyphenols contain a basic structure of C6-C3-C6, which includes a phenyl propane unit and a benzoic ring and (Heim et al., 2002) (Fig. 1). The main classes of flavonoids include flavones, flavanones, flavonols, flavanonols, isoflavones, flavan-3-ols (i.e., catechins), chalcones,
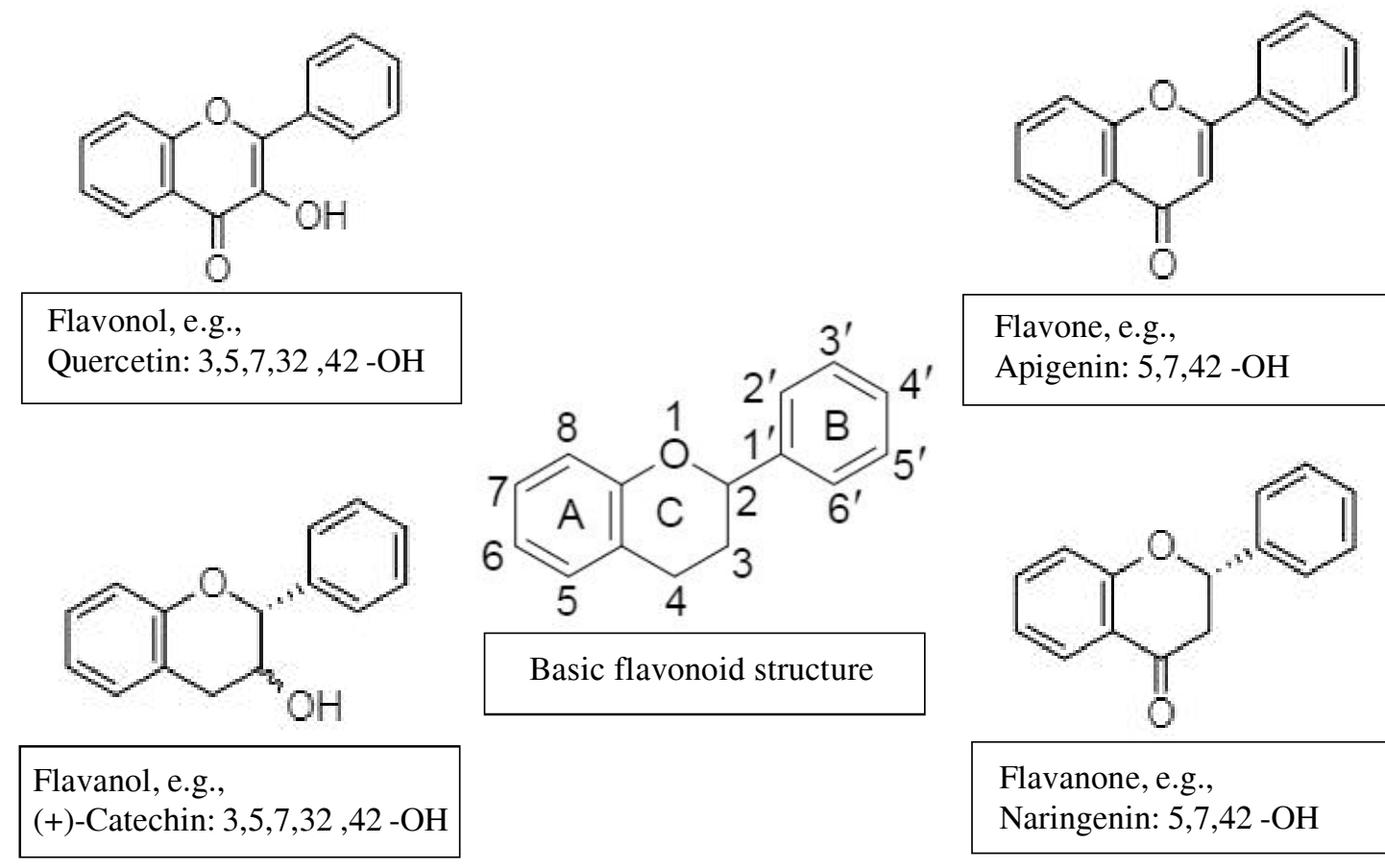

Flavone, e.g.,

Apigenin: 5,7,42-OH

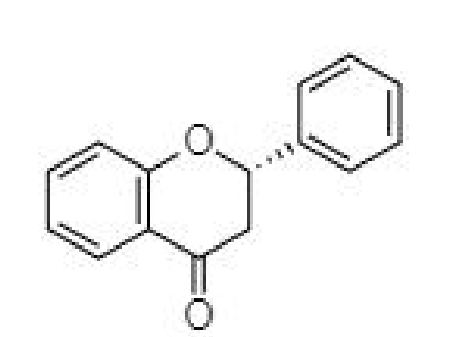

Flavanone, e.g.,

Naringenin: 5,7,42-OH

Fig. 1. Basic flavonoid structures and its few derivatives 
anthocyanidins, and leukoanthocyanidins depending upon modification of the basic structures. Many flavonoids are present in different propolis types (e.g. chrysin, galangin, genkwanin, apigenin, kaempferol, tectochrysin, pinocembrin, and methoxyflavone, pilloin and pinostrobinchalcone) and all of them are well known for their antibacterial and antioxidant properties (Maciejewicz et al., 2002), while vestitol and medicarpin (isoflavonoids components) are the most abundant compounds only found in the Brazilian red propolis (Morsy et al., 2015). Flavonoids (e.g., chrysin) also seem to be the responsible factor which gives propolis its specific color (Kêdzia and Holderna-Kędzia 2006). Therefore, propolis with similar color exhibits a greater resemblance for the chemical composition (Alencar et al., 2007). Flavonoids are characterized by powerful antibacterial and antioxidative activities. Flavonoids as antioxidants are capable to donate their own electrons to free radicals preventing the chain reaction of peroxidation in the body.

Terpinenes: All propolis types mainly have similar specific odor due to aromatic volatile terpinenes (monoterpenes, diterpenes, sesquiterpenes, and triterpenes) content (Yang et al., 2010). Yang et al. (2010) identified twenty-eight major terpene components in 23 different propolis types collected from different places in China, including eucalyptol, cedrol, guaiacol, benzyl alcohol and phenylethyl alcohol. The same study of Yang et al. (2010) reported that forty-four of 83 common volatiles (e.g., alcohols, aromatics, aldehydes, esters, and organic acids) were aroma-active compounds rather than the terpenes.

Terpene components are found in small amount in all propolis types amounting to about $0.5 \%$ (Górecka et al., 2014), while the most abundant active components in propolis are phenolic constitutes (e.g., phenols, phenolic acids, phenolic aldehydes, and their esters, ketophenols, coumarins) and flavonoids (aglycones of glycosidic substances present naturally in plants) (Górecka et al., 2014).

Other components: All bee propolis types contain plant waxes, a mixture of fatty acids, sterols, and their esters, as well as of aliphatic hydrocarbons (Górecka et al., 2014; Soltan et al., 2016). In some propolis types (e.g. the Egyptian brown propolis), the bioactive hexane fraction consisting of a high proportion of fatty acids was the most abundant component, it was higher than the flavonoids part (Morsy et al., 2015). Beeswax mainly contains myricyl esters of palmitic and cerotic acids, melissic and cerotic acid, saturated hydrocarbons particularly heptadecane, octadecane, eicosane, tricosane, and unsaturated hydrocarbons such as cholestrilene and eicosene (Kêdzia and Holderna-Kędzia, 2006). Beeswax also may contain small quantity of carotenoids, alcohols, lactones, and cholesterol esters.

\section{Propolis on ruminal microbial fermentation and digestion}

Different bioactive compounds of plant origins have antimicrobial effects (Patra, 2012), which consequently modulate ruminal fermentation by inhibiting or stimulating a particular type of ruminal microorganism groups (Patra et al., 2009). Propolis is also rich in plant bioactive compounds as discussed in the earlier section, which cause modulation of ruminal fermentation. Unlike the most common dietary feed additives (e.g. ionophores or essential oils), the literature reported that different types of propolis had less adverse effects or enhanced the dry matter (DM) intake and ruminal nutrient degradability. This was clearly observed in crossbred buffalo (Murrah $\times$ Jafarabadi) steers fed Brazilian propolis collected from the apiary located in sites containing eucalyptus (Eucalyptus sp.) surrounded by native forest and alecrim-docampo (Baccharis dracunculifolia) (Costa et al., 
2012), growing lambs fed crude brown propolis 13 g/kg (DM) (da Silva et al., 2019), and primiparous lactating dairy Holstein cows fed three different propolis types (Aguiar et al., 2014). Most of literature confirmed the better energy utilization by propolis supplementation. Improvements in total and/or individual short chain fatty acids (SCFA) production were observed in many studies, which confirm the positive effect of different types of propolis on rumen microbial fermentation. Phenolic compounds present in propolis extract may improve ruminal fermentation conse-quently influencing nutrient intake (de Paula et al., 2016).

Brazilian red propolis and Egyptian brown propolis $(125,250$, or $500 \mu \mathrm{g} / 500 \mathrm{mg}$ of dietary dry matter) increased in vitro concentrations of total SCFA and/or individual concentrations of acetate, propionate and valerate independent of the type, color or site of collection (Morsy et al., 2015). The authors attributed the increase in total SCFA mainly to a marked increase in acetate (the major contributor to SCFA) production by $45 \%$ compared to monensin. The same study (Morsy et al., 2015) confirmed the improvement in the ruminal degradation of organic matter with propolis. Similarly, increases in total SCFA and butyrate concentrations were observed for crossbred buffalo steers fed different doses of Brazilian propolis, and this effect was associated with the increase in total tract DM digestibility (Costa et al., 2012). Increased SCFA concentrations in the rumen and DM digestibility were also reported by Stradiotti Júnior et al. (2004) in Holstein steers fed a diet containing $65 \%$ forage and $35 \%$ supplemented with propolis in the concentrate. Santos et al. (2016) observed an increase in propionate production associated with reduction in methane $\left(\mathrm{CH}_{4}\right)$ production due to supplementation of green propolis (the unique propolis types which contain artepillin $\mathrm{C}$ as a major component).
The only studies that reported no effect of propolis in SCFA used propolis in the form of ethanolic solutions (70\%) for dairy goats (Lana et al., 2005; 2007), therefore the effects of ethanol itself can interfere with the enhancement effect of propolis on rumen microbial fermentation. It seems that the anti-oxidative activity of chemical constituents can optimize the fermentation process through reducing the overproduction of reactive species (Soltan et al., 2018). It is worth noting that plant bioactive components which possess antioxidant together with antibacterial properties (e.g. moringa root barks) had similar enhancements of SCFA and nutrient digestibility effects as propolis (Soltan et al., 2018).

Increased SCFA or DM digestibility found for propolis can be conjugated or not with reduction in rumen ammonia concentration and protein degradability. Brazilian propolis extracts supplemented to dairy cows reduced the dietary crude protein degradability and ammonia concentration, while increased the intestinal digestibility of crude protein (Ozturk et al., 2010; Aguiar et al., 2014). However, the authors did not report any information about the place of propolis collection or chemical composition. Costa et al. (2012) observed an increase of the DM digestibility without reduction in ammonia production in buffalo steers. All these findings may refer that different propolis extracts may enhance the ruminal nutrient degradability while reduce the deamination of amino acids and/or growth rate of amino acid-fermenting bacteria.

Ruminal methane $\left(\mathrm{CH}_{4}\right)$ production is an important source of greenhouse gas emission in ruminant production systems (Patra, 2014). Therefore, many strategies have been explored to decrease $\mathrm{CH}_{4}$ production in ruminants (Patra, 2016). Propolis has been evaluated to decrease energy loss in the form of $\mathrm{CH}_{4}$ production. Until recently, only a few reports are available in the literature studying the effects of propolis on $\mathrm{CH}_{4}$ inhibition. Propolis is used as a natural 
alternative to dietary antibiotics (e.g., monensin) for modifying microbial fermentation towards enhancing the SCFA and decreasing ruminal methanogenesis. The antimicrobial effect of propolis against specific microbial strains may play a role in this alteration of ruminal fermentation; however, these effects are not well studied for rumen microorganisms. It was found that propolis is active compound against Gram positive bacteria (Hasan et al., 2014). Presence of specific chemical components in propolis could limit the bacterial growth through inhibiting bacterial replication with disrupted cell division (Sabir, 2005). Flavonoids and terpinenes can exert antibacterial effects of propolis through changing transport systems of nutrients and structure of organic compounds (Seven et al., 2018).

Most of the strategies used to reduce $\mathrm{CH}_{4}$ may adversely affect the animal performance (Patra, 2016), but the adverse effect of propolis was relatively less. Morsy et al. (2011) found that green and alamo Brazilian propolis presented a similar inhibition on $\mathrm{CH}_{4}$ production without negative effect on the gas production and degradability of organic matter in vitro. Santos et al. (2016) reported the decrease of $\mathrm{CH}_{4}$ production was a result of modifying the rumen fermentation towards more propionate production. Both Brazilian red and Egyptian brown propolis extracts found to have antiprotozoal effect. Thus, $\mathrm{CH}_{4}$ reduction caused by propolis can also be attributed to its antiprotozoal effect, since protozoa produce hydrogen, a substrate for the methanogens that are ecto and endo symbiotically associated with protozoa (Morsy et al., 2015).

Propolis can act at post ruminally enhancing the total tract digestibility through controlling the intestinal helminthiasis. Morsy et al. (2013) found that ethanolic extract of red propolis (3 g/ewe/day) significantly reduced the total fecal nematode egg count in grazing Santa Inês ewes during the flushing period.

\section{Propolis on ruminal microbiota}

Various plant bioactive compounds exert antimicrobial effects depending upon dose, type, species and strains of bacteria (Patra, 2012). Propolis also contains various phenolic compounds that exert antimicrobial effects against wide range of microorganisms. The antimicrobial effects of propolis may be effective against a selective group of microbiota improving ruminal fermentation as particularly Gram negative bacteria were more sensitive than the Gram positive ruminal bacteria, which was in contrast to the monensin (Prado et al., 2010). de Aguira et al. (2013) studied antimicrobial activity of three Brazilian propolis extracts (containing naringenin, caffeic acid, $p$-coumaric acid chrysin and artepillin C) against different ruminal bacteria in vitro. The propolis extracts inhibited the growth of Ruminococcus flavefaciens, Ruminococcus albus 7, Fibro-bacter succinogenes, Butyrivibrio fibrisolvens, Prevotella albensis and Streptococcus bovis, but R. albus 20, Prevotella bryantii and Ruminobacter amylophilus were resistant to all the extracts. Propolis was effective against the hyper ammonia producing bacteria Clostridium aminophilum and Peptostreptococcus sp. (Aguira et al., 2013), which might be responsible for decreased ruminal ammonia concentrations in some studies (Ozturk et al., 2010; de Aguiar et al., 2014; Ehtesham et al., 2018). The reduction of protein degradation and ammonia concentrations in the rumen may improve protein utilization efficiency (Patra et al., 2018) as discussed in earlier section. Naringenin present in the Brazilian propolis had greater antibacterial action against the ruminal bacteria than other bioactive compounds (de Aguiar et al., 2013). In another study, the growth of ruminal S.bovis, E.coli and Mitsuokella jalaludinii was not affected by 
propolis extract at $1 \mathrm{mg} / \mathrm{mL}$ of propolis extract, but the growth of Clostridium bifermentans (a proteolytic bacterium) was inhibited by propolis (de Aguiar et al., 2014). Ehtesham et al. (2018) evaluated different concentrations of Iranian propolis in medium (concentrate: forage, 60:40) and high (concentrate: forage, 80:20) diets on ruminal microorganisms and ruminal fermentation. In this study, Iranian propolis inhibited the growth of $R$. albus, Prevotella bryantii, fibrolytic and amylolytic bacteria in a dose and diet dependent manner with greater inhibition in medium concentrate diet, but interestingly, at low concentration of propolis in the high concentrate diet, growth of all the microorganisms were stimulated (Ehtesham et al., 2018). The propolis-based product $(1.2 \mathrm{~g} / \mathrm{kg}$ diet $)$ rich in phenolic compounds, particularly, artepicillin $\mathrm{C}$ enhanced Butyrivibrio fibrisolvens count in the rumen, which increased the concentration of cis 9 trans 11 C18:2 CLA (a beneficial fatty acid) in milk (Yoshimura et al., 2018). In different studies, propolis was also shown to decrease the rumen ciliate protozoal populations (Morsy et al., 2015; Yoshimura et al., 2018) with a concentration dependent manner (Ehtesham et al., 2018). Methanogens populations were also inhibited by propolis (Ehtesham et al., 2018), which together with reduced protozoal numbers may be responsible for reduction of methane production ( Morsy et al., 2011; Santos et al., 2016; Ehtesham et al., 2018). From the above discussion, it is clear that the effect of propolis on the ruminal microbial population is influenced by dose, diet, type and strains of bacteria, which are the main factors determining the responses of propolis on ruminal fermentation, nutrient digestibility and subsequently ruminant production in addition to its strong antioxidant properties.

\section{Propolis on ruminant production performance}

Propolis supplementation also enhances the quantity and quality of animal products (milk or meat) compared to the dietary monensin (the most effective feed additive for ruminants). Santa Ines ewes treated with Brazilian red propolis extracts ( $3 \mathrm{~g} / \mathrm{animal} / \mathrm{day}$ ) for 21 days after parturition significantly enhanced milk yield, fat, lactose, protein yield, and energy corrected milk, while decreased somatic cell counts (Morsy et al., 2016). In dairy cows, the addition of three different types of brown propolis enhanced milk yield, antioxidant capacity of milk and quality of milk fat composition by improving the content of conjugated linoleic acid isomers, and decreasing the n6:n3 ratio (Aguiar et al., 2014). Chinese propolis supplemented to the diet of Barki ewes increased milk yield and milk fat with enhancement in oxidative stress conditions displayed by decreasing antioxidant enzymatic activities such as malondialdehyde, superoxide dismutase, horseradish peroxidase and nitric oxide production (Shedeed et al., 2019). Ewes treated with $3 \mathrm{~g}$ red propolis extract showed significant improvements in milk conversion ratio and average daily gain of their lambs (Morsy et al., 2016). Similarly, Shedeed et al. (2019) observed significant increase in weaning weight of lambs born to ewes fed $5 \mathrm{~g} / \mathrm{kg}$ diet Chinese propolis at week 8 after birth. Improvement in milk quality and quantity from dams fed with propolis may be responsible for better performance of newborn ruminants. Also, transfer of the residuals of propolis active components into the milk may improve the newborn health and immunological status because dietary isoflavonoids can be transferred into the milk in different concentrations depending on the composition of the diet fed to animals (Kasparovska et al., 2016). However, no studies have been conducted to confirm this for propolis. Propolis is recently used in food preservation (Seven et al., 2018), thus presence of residuals of propolis active components into the milk may affect the milk preservation time and the quality of the dairy 
products, which are widely consumed by infants and children throughout the world.

Most of the published literature suggests that the dietary supplementation of propolis positively affects the performance and/or health status of pre-weaned ruminants. Recently, Cecere et al. (2020) found that feeding of milk mixed with propolis extract at different doses $(0,150,200$, and $250 \mu \mathrm{L}$ of propolis/kg of body weight/day) significantly increased weight gain, antimicrobial, antioxidant, and immune responses (serum concentration of immunoglobulin A) in suckling Lacaune lambs. Holstein calves supplemented with flavonoids extracted from propolis $\left(3.6 \times 10^{-3} \mathrm{~g} / \mathrm{kg}\right.$ body weight $)$ showed higher serum immunoglobulin $\mathrm{G}$ concentrations at the first three weeks of animal life, greater body weight during the first five weeks of age, and had higher starter intake at younger ages when compared with calves fed diet supplemented with lower doses or without any supplementations (Yaghoubi et al., 2008). Slanzon et al. (2019) found that newborn Holstein calves fed on $6 \mathrm{~L} / \mathrm{d}$ of whole milk and $4 \mathrm{~mL} / \mathrm{d}$ of red propolis ethanolic extract for 56 days had improved calf health while reduced the incidence of diarrhea, medical costs and interventions for veterinary medication.

Propolis as a feed supplementation may exceed the dietary antibiotics as growth promoters. The supplementation of propolis extract (containing $0.054 \mathrm{mg} / \mathrm{g}$ of total flavonoids) to the diet of feedlot-finished Nellore bulls significantly improved body weight and increased feed conversions compared to a monensin-supplemented diet (Zawadzki et al., 2011). Brown propolis either in crude form or ethanolic extract enhances the carcass yield of lambs and alters the fatty acid profile of meat, reducing saturated fatty acid content and increasing unsaturated ones (da Silva et al.,
2019). It can be concluded that propolis supplementation may enhance the ruminant performance through balancing rumen microbial fermentation with a consequent less prevalence of pathogens and more nutrient utilization.

\section{Nano propolis}

Nanoparticle has at least one dimension smaller than $100 \mathrm{~nm}$ and potentially as small as molecular length scales and behaves as a whole unit for its transport with altered chemical and biological properties (Seven et al., 2018; Patra, 2019). Nanotechnology is currently an area of intense scientific interest owing to a great variety of potential applications. Propolis was recently used in its nano-from to be more effective biologically (Seven et al., 2018). Nano-propolis can be prepared by encapsulation methods by casein micelles or chitosan-based nano-inmicroparticle carriers (Sahlan et al., 2013; Elbaz et al., 2016).

Due to the wax content naturally present in propolis, all propolis types are not hydrophilic, but nano-propolis had higher water solubility compared to crude or extracted propolis. Nanopropolis can more easily penetrate the outer membrane of bacterial cell walls, thus the activity of antibacterial bioactive components present in propolis can be much higher than the normal propolis form (Seven et al., 2018). Hasan et al. (2014) observed that the antibacterial efficiency of nano-propolis against Bacilus subtilis, S. aureus, E. coli and Salmonella sp. was more effective (206, 212, 227, and 230\% respectively) compared to normal propolis form. Due to the high antibacterial and antioxidant activity of nano-propolis, it was used to control of the pathogenic bacterial and fungal diseases (Hasan et al., 2014) or to reduce liver cancer cells (Elbaz et al., 2016). However, no studies of different types of nanopropolis as dietary feed additive were done for ruminants. 


\section{Conclusion}

The chemical composition of propolis is highly variable depending upon different plant species available in the sites for collection by honeybees. The most common bioactive components found in different propolis types despite of their site of collection or color are phenolic acids, flavonoids and terpene components. Despite this variability, different propolis types act mainly through more potent mechanisms of action (e.g. antimicrobial and antioxidant), which modify ruminal microbial fermentation and confer better antioxidant status resulting in improvement of animal performance and health. In general, propolis had no adverse effects or enhances the dry matter intake alongside with enhancements of

\section{REFERENCES}

Aguiar SCD, De Paula EM, Yoshimura EH, Dos Santos WBR, Machado E et al., 2014. Effects of phenolic compounds in propolis on digestive and ruminal parameters in dairy cows. Rev Brasileira de Zootecnia, 43(4): 197-206, doi: 10.1590/S1516-35982014000400006

Alencar SM, Oldoni TLC, Castro ML, Cabral ISR, Costa-Neto CM et al., 2007. Chemical composition and biological activity of a new type of Brazilian propolis: red propolis. J Ethnopharmacol, 113(2): 278-283, doi: 10.1016/j.jep.2007.06.005

Cecere BGO, da Silva AS, Molosse VL, Alba DF, Leal KW et al., 2020. Addition of propolis to milk improves lactating lamb's growth: effect on antimicrobial, antioxidant and immune responses in animals. Small Rum Res, doi: 10.1016/j.smallrumres.2020. 106265

Costa JBGJ, Zeoula LM, Franco SL, de Moura LPP, Valero MV et al., 2012. Effect of propolis product on digestibility and ruminal parameters in buffaloes consuming a forage based diet, Ital J Anim Sci, 11(4): 441-448, doi: 10.4081/ijas.2012.e78

da Silva JA, Ítavo CCBF, Ítavo LCV, da GraçaMorais M, da Silva PCG et al., 2019. Dietary addition of crude form or ethanol extract of brown nutrient utilization. It positively affects rumen microbial fermentation through improving total and/or individual short chain fatty acids production, and on rumen nitrogen metabolism. Propolis also may manipulate ruminal fermentation towards less methane formation. The quantity and quality of animal products (milk or meat) can be enhanced by propolis compared to the dietary monensin. It can be concluded that presence of phytochemicals in propolis acting as antioxidant together with antibacterial substances may lead to better ruminal fermentation and nutritional effects for ruminants. The widely varied bioactive composition of propolis is a challenge to optimize the dose level and consistently obtain the results.

propolis as nutritional additive on behaviour, productive performance and carcass traits of lambs in feedlot. J Anim Feed Sci, 28(1): 3140, doi: 10.22358/jafs/105442/2019

de Aguiar SC, Zeoula LM, Franco SL, Peres LP and Arcuri PB, 2013. Antimicrobial activity of Brazilian propolis extracts against rumen bacteria in vitro. World J Microbiol Biotechnol, 29: 1951-1959, doi: 10.1007/ s11274-013-1361-x

de Aguiar SC, Zeoula LM, do Prado OPP, Arcuri PB and Forano E, 2014. Characterization of rumen bacterial strains isolated from enrichments of rumen content in the presence of propolis. World J Microbiol Biotechnol, 30(11): 2917-2926, doi: 10.1007/s11274014-1719-8

de Paula EM, Samensari RB, Machado E, Pereira LM, Maia FJ et al., 2016. Effects of phenolic compounds on ruminal protozoa population, ruminal fermentation, and digestion in water buf-faloes. Livest Sci, 185: 136-141, doi: 10.1016/j.livsci.2016. 01.021

Ehtesham S, Vakili AR, Danesh Mesgaran M and Bankova V, 2018. The Effects of phenolic compounds in Iranian propolis extracts on in vitro rumen fermentation, methane production 
and microbial population. Iran J Appl Anim Sci, 8(1): 33-41

Elbaz NM, Khalil IA, Abd-Rabou AA and El-Sherbiny IM, 2016. Chitosan-based nano-inmicroparticle carriers for enhanced oral delivery and anticancer activity of propolis. Int J Biol Macromol, 92: 254-269, doi: 10.1016/j.ijbiomac.2016.07.024

Górecka AK, Rzepecka-Stojko A, Górecki M, Stojko J, Sosada M et al., 2014. Structure and antioxidant activity of polyphenols derived from propolis. Molecules, 19(1): 78-101, doi: 10.3390/molecules 19010078

Hasan AEZ, Ambarsari L, Widjaja WK and Prasetyo R, 2014. Potency of nanopropolis stingless bee Trigona spp Indonesia as antibacterial agent. IOSR J Pharm, 4(12): 1-9., doi: 10.6084/ M9.FIGSHARE. 1294843.V1

Heim KE, Tagliaferro AR and Bobilya DJ, 2002. Flavonoid antioxidants: chemistry, metabolism and structure-activity relationships. J Nutr Biochem, 13(10): 572584, doi: 10.1016/S0955-2863(02) 00208-5

Hosseini SM, Azghandi VM, Ahani S and Nourmohammadi R, 2016. Effect of bee pollen and propolis (bee glue) on growth performance and biomarkers of heat stress in broiler 359 chickens reared under high ambient temperature. J Anim Feed Sci, 25: 4551, doi: $10.22358 /$ jafs/65586/2016

Kaèániová M, Rovná K, Arpášová H, Cuboò J, Hleba L et al., 2012. In vitro and in vivo antimicrobial activity of propolis on the microbiota from gastrointestinal tract of chickens. J Environ Sci Health A Tox Hazard Subst Environ Eng, 47: 1665-71, doi: 0.1080/ 10934529.2012.687248

Kasparovska J, Pecinkova M, Dadakova K, Krizova L, Hadrova $\mathrm{S}$ et al., 2016. Effects of isoflavoneenriched feed on the rumen microbiota in dairy cows. PLoS One, 11(4): e0154642, doi: 10.1371/journal.pone. 0154642

Kêdzia B and Hołderna-Kędzia E, 2006. The bee products in the nutrition and supplementation. Post Fitoter, 4 (1): 13-221
Klaric I, Pavic M, Miskulin I, Blazicevic V, Dumic A et al., 2018. Influence of dietary supplementation of propolis and bee pollen on liver pathology in broiler chickens. Animals (Basel), 8: 54, doi: 10.3390/ ani8040054

Kocot J, Kiłczykowska M, Luchowska-Kocot D, Kurzepa J and Musik I, 2018. Antioxidant potential of propolis, bee pollen, and royal jelly: possible medical application. Oxid Med Cell Longev, 2018: 7074209, doi: 10.1155/ 2018/7074209

Lana RP, Camardelli MML, Queiroz AC, Rodrigues MT, Eifert EC et al., 2005. Soybean oil and propolis in the diets of dairy goats. R Bras Zootec, 34(2): 650-658, doi: 10.1590/S151635982005000200035

Lana RP, Camardelli MML, Rodrigues MT, Eifert EC, Oliveira MVM et al., 2007. Soybean oil and propolis in the diets of dairy goats: intake of nutrients and ruminal metabolism. R Bras Zootec, 36(1): 191-197, doi: 10.1590/S151635982005000200035

Maciejewicz W, Daniewski M, Dzido T and Bal K, 2002. GC-MS and HPLC analysis of phenolic acids extracted from propolis and from Populusnigra bud exudate. Chem. Anal, 47: 21-30

Marcucci MC, Rodriguez J, Ferrerez F, Bankova V, Groto R et al., 1998. Chemical composition of Brazilian propolis from São Paulo State. Z Naturforsch C, 53(1-2): 117-119, doi: $10.1515 /$ znc-1998-1-220

Morsy AS, Soltan YA, Elzaiat HM, Sallam SMA, Alencar SM et al., 2011. Effect of two types of Brazilian propolis extracts on rumen gas and methane production and truly degradability in vitro. J Middle East North Afr Sci, 4(1): 446-456

Morsy AS, Abdalla AL, Soltan YA, Sallam SMA, ElAzrak KM et al., 2013. Effect of Brazilian red propolis administration on hematological, biochemical variables and parasitic response of Santa Inês ewes during and after flushing period. Trop Anim Health Prod, 45(7): 16091618, doi: 10.1007/s11250-013-0406-3 
Morsy AS, Soltan YA, Sallam SMA, Kreuzer M, Alencar $\mathrm{SM}$ et al., 2015. Comparison of the in vitro efficiency of supplementary bee propolis of different origin in enhancing ruminal nutrient degradation and mitigating methane formation. Anim Feed Sci Technol, 199(1): 51-60, doi: 10.1016/j.anifeedsci.2014.11.004

Morsy AS, Soltan YA, Sallam SMA, Alencar SM and Abdalla AL, 2016. Impact of Brazilian red propolis extract on blood metabolites, milk production, and lamb performance of Santa Ines ewes. Trop Anim Health Prod, 48(5): 10431050, doi: 10.1007/s11250-016-1054-1

Ozturk H, Pekcan M, Sireli M and Fidanci UR, 2010. Effects of propolis on in vitro rumen microbial fermentation. Üniversitesi Veteriner Fakültesi Dergisi, 57(1): 217-221, doi: 10.1501/ Vetfak_0000002428

Patra AK and Aschenbach JR, 2018. Ureases in the gastrointestinal tracts of ruminant and monogastric animals and their implication in urea-N/ammonia metabolism: A review. J Adv Res, 13: 39-50, doi: 10.1016/j.jare. 2018.02.005

Patra AK and Saxena J, 2009. Dietary phytochemicals as rumen modifiers: A review of the effects on microbial populations. Antonie van Leeuwenhoek, 96(4): 363-375, doi: 10.1007/ s10482-009-9364-1

Patra AK, 2012. An overview of antimicrobial properties of different classes of phytochemicals. In: Patra AK editor. Diet Phytochemicals and Microbes: Dorrecht, Springer Netherlands, pp1-32, doi: 10.1007/ 978-94-007-3926-0_1

Patra AK, 2014. Trends and projected estimates of GHG emissions from Indian livestock in comparison with GHG emissions from world and developing countries. Asian-Australas J Anim Sci, 27(4): 592-599, doi: 10.5713/ ajas.2013.13342

Patra AK, 2016. Recent advances in measurement and dietary mitigation of enteric methane emissions in ruminants. Front Vet Sci, 3: 117, doi: 10.3389/fvets.2016.00039

Patra AK, 2019. Are nanomaterials potential new generation antimicrobial feed additives in livestock? Indian J Anim Hlth, 58(Special): 105-120

Prado OPP, Zeoula LM, Moura LPP, Franco SL, Paiva SB et al., 2010. Isolation and expeditious morphological, biochemical and kinetic characterization of propolis-tolerant ruminal bacteria. Rev Bras de Zootec, 39(9): 20482054, doi: 10.1590/S151635982010000900025

Prakatur I, Miskulin M, Pavic M, Marjanovic K, Blazicevic $\mathrm{V}$ et al., 2019. Intestinal morphology in broiler chickens supplemented with propolis and bee pollen. Animals (Basel), 9: 301, doi: 10.3390/ani9060301

Rufatto LC, Paola L, Charlene G, Christine T, Sylvie B et al., 2018. Brazilian red propolis: chemical composition and antibacterial activity determined using bio guided fractionation. Microbiol Res, 214: 74-82, doi: 10.1016/ j.micres.2018.05.003

Sabir A, 2005. The inflammatory response on rat dental pulp following ethanolic extract of propolis (EEP) application. Maj Ked Gigi (Dent J), 38: 77-83

Sahlan M and Supardi T, 2013. Encapsulation of Indonesian propolis by casein micelle. Int $\mathbf{J}$ Pharm Bio Sci, 4(1): 297-305

Santos NW, Zeoula LM, Yoshimura EH, Machado E, Macheboeuf D et al., 2016. Brazilian propolis extract used as an additive to decrease methane emissions from the rumen microbial population in vitro. Trop Anim Health Prod, 48(5): 10511056, doi: 10.1007/s11250-016-1062-1

Scheller S, Wilczok T, Imielski S, Król W, Gabry ś J et al., 1990. Free radical scavenging by ethanol extract of propolis. Int J Radiat Biol, 57(3): 461-465, doi: 10.1080/09553009014552601

Seven I, Aksu T and Tatli Seven P, 2010. The effects of propolis on biochemical parameters and activity of antioxidant enzymes in broilers exposed to lead-induced oxidative stress. Asian-Australas J Anim Sci, 23 (11): 14821489, doi: 10.5713/ajas.2010.10009

Seven PT, Seven I, Baykalir BG, Mutlu SI and Salem 
AZM, 2018. Nanotechnology and nanopropolis in animal production and health: an overview. Italian J Anim Sci,17(4): 921-930, doi: 10.1080/1828051X.2018.1448726

Shedeed HA, Farrag B, Elwakeel EA, Abd El-Hamid IS and El-Rayes MA-H, 2019. Propolis supplementation improved productivity, oxidative status, and immune response of Barki ewes and lambs. Vet World, 12(6): 834843, doi: 10.14202/vetworld. 2019.834-843

Slanzon GS, Toledo AF, Silva AP, Coelho MG, da Silva MD et al., 2019. Red propolis as an additive for pre weaned dairy calves: effect on growth performance, health, and selected blood parameters. J Dairy Sci, 102(10): 8952-8962, doi: $10.3168 /$ jds.2019-16646

Soltan YA, Hashem NM, Morsy AS, El-Azrak KM, Nour El-Din A et al., 2018. Comparative effects of Moringa oleifera root bark and monensin supplementations on ruminal fermentation, nutrient digestibility and growth performance of growing lambs. Anim Feed Sci Technol, 235: 189-201, doi: 10.1016/j.anifeedsci. 2017.11.021

Soltan YA, Morsy AS, Sallam SMA and Abdalla AL, 2016. Propolis as natural feed additive in ruminant diets; can propolis affect the ruminants performance? -A review. Egyptian J Nutr Feed, 19(1): 73-79

Stradiotti Junior D, Queiroz AC, Lana RP, Pacheco CG, Eifert EC et al., 2004. Effect of the propolis on amino acids deamination and ruminal fermentation. Rev Bras de Zootec, 33(4): 1086-1092, doi: 10.1590/S151635982004000400029

Volpi N, 2004. Separation of flavonoids and phenolic acids from propolis by capillary zoneel ectrophoresis. Electrophoresis, 25: 18721878, doi: 10.1002/elps.200405949

Yaghoubi SM, Ghorbani GR, Rahmani HR and Nikkah A, 2008. Growth, weaning performance and blood indicators of humoral immunity in Holstein calves fed supplemental flavonoids. J Anim Physiol Anim Nutr, 92(4): 456-462, doi: 10.1111/j.1439-0396.2007.00734.x

Yang C, Luo L, Zhang H, Yang X, Lva Y and Song H, 2010. Common aroma-active components of propolis from 23 regions of China. J Sci Food Agric, 90: 1268-1282, doi: 10.1002/jsfa.3969

Yoshimura EH, Santos NW, Machado E, Agustinho BC, Pereira LM et al., 2018. Effects of dairy cow diets supplied with flaxseed oil and propolis extract, with or without vitamin E, on the ruminal microbiota, biohydrogenation, and digestion. Anim Feed Sci Technol, 241: 163-172, doi: 10.1016/j.anifeedsci .2018 .04 .024

Zafarnejad K, Afzali N and Rajabzadeh M, 2017. Effect of bee glue on growth performance and immune response of broiler chickens. J App Anim Res, 45: 280-284, doi: 10.1080/ 09712119.2016 .1174130

Zawadzki F, Prado IN, Marques JA, Zeoula LM, Rotta PP et al., 2011. Sodium monensin or propolis extract in the diets of feedlot-finished bulls: effects on animal performance and carcass characteristics. J Anim Feed Sci, 20(1): 1625, doi: $10.22358 /$ jafs/66153/2011

Zhou JH, Li Y, Zhao J, Xue XF, Wu LM et al., 2008. Geographical traceability of propolis by highperformance liquid-chromatography fingerprints. Food Chem, 108(2): 749-759, doi: 10.1016/j.foodchem. 2007.11.009

Received-19.10.2020, Accepted - 22.11.2020, Published - 01.12.2020 